\title{
Diagnóstico tardio de HIV na terceira idade: uma análise de reportagens veiculadas na mídia
}

\author{
Late HIV diagnosis in third age: an analysis of \\ news articles in media
}

\section{Amanda Bahia Fonseca' ${ }^{1}$ () Maria Aline Souza Batista ${ }^{2} \odot$ Ramiro Rodrigues Coni Santana ${ }^{3}$}

1'Autora para correspondência. Centro Universitário Maurício de Nassau (Salvador). Bahia, Brasil. amandabahia2012@hotmail.com ${ }^{2}$ Centro Universitário Maurício de Nassau (Salvador). Bahia, Brasil. mariaalinesbatista@gmail.com 3Universidade Federal da Bahia (Salvador). Bahia, Brasil. prof.rconi@gmail.com

\begin{abstract}
RESUMO | Esse artigo apresenta resultados de uma pesquisa qualitativa exploratória, que buscou analisar a visão das mídias em relação ao sexo na terceira idade. Foram utilizadas cinco reportagens sobre a forma que as mídias auxiliam como ferramenta informativa sobre HIV na terceira idade. Os motivos dos idosos serem vulneráveis às IST (infecções sexualmente transmissíveis) a partir de dados midiáticos são diagnóstico tardio da doença pelos profissionais de saúde, que ao terem acesso as demandas dos pacientes, a priori, atribuem qualquer outro diagnóstico ao idoso, não considerando a possibilidade de ser um quadro clínico de HIV positivo; preconceitos, estereótipos e discriminações sociais perante a atividade sexual na terceira idade, pela crença social de vida sexual inativa da pessoa idosa. Diante destas problemáticas, se faz necessário trabalhar nas políticas públicas questões sobre soropositividade das pessoas na terceira idade, intervenções através da criação de campanhas, cartilhas e outras sobre a importância do uso do preservativo, importância do olhar humanizado do profissional de saúde voltado para a população idosa, e olhar mais minucioso e sensível aos sinais e sintomas da doença para que o tratamento possa ser praticado na fase inicial da infecção.
\end{abstract}

PALAVRAS-CHAVE: Infecções por HIV. Diagnóstico tardio. Preconceito. Estereótipo. Discriminação. Mídias.

\begin{abstract}
This article shows exploratory qualitative research outcomes that analyze how social media touch upon the theme of the sexual relations among elderly people. It was utilized five news reports published on newspapers that talk about how social media works as an informative tool about HIV among elderly people. The reasons to elderly people are vulnerable to sexually transmitted diseases, according to social media datas, can be the late diagnosis; prejudice, stereotypes and, social discrimination in relation to the sexual relations among elderly people, as a result of social representation that affirms there is not sexual practices in old age. As as result of this problem, it is necessary to work on public policies on issues of seropositivity in the old age, as well as interventions through the creation of campaigns, booklets and others approaches on the importance of condom use. The importance of the humanized approach of work of health professionals focused on older population, and a more refined look at the signs and symptoms of the HIV disease, so that treatment can be practiced in the early stages of infection.
\end{abstract}

KEYWORDS: HIV infection. Late diagnosis. Discrimination. Stereotypes. Prejudice. Social media. 


\section{Introdução}

Em seus primórdios a AIDS (Síndrome da Imunodeficiência Adquirida) surgiu disfarçada em outras doenças, como a pneumonia atípica e um câncer raro nas cidades norte americanas de Los Angeles, São Francisco e Nova York, na década de 1980. Essa descoberta foi feita pelos Centros de Estudos dos Estados Unidos da América, cujo público alvo inicial era homens jovens e homossexuais que viviam nessas cidades. Contudo, nos locais próximos a Savana, localizados na África, essa epidemia passou despercebida da mídia e da ciência. Diante desses fatos, o HIV (Vírus da Imunodeficiência Adquirida) originou a epidemia da AIDS na África em 1970 (Bastos, 2006).

Além da negligência da mídia e da ciência, o HIV perpassava por determinados grupos de pessoas que foram denominados de $4 \mathrm{H}$. Esse nome foi dado, pois entre eles estavam os homossexuais, que faziam sexo sem o uso de preservativo; os haitianos, pois durante a construção das políticas do Haiti o número de desigualdades sociais e das minorias psicológicas que eram comercializadas e exploradas sexualmente sem condições mínimas de sexo seguro, teve um aumento exorbitante.

Ainda no referido grupo estavam os hemofílicos, pois na produção de hemoderivados para tratamento sanguíneo recebiam grandes amostras de sangue e que em sua maioria estavam contaminados pelo vírus HIV; e por último os heroidanos, que utilizavam drogas injetáveis e eram infectados pelo vírus da imunodeficiência a partir do uso de seringas de maneira inadequada. O compartilhamento dessas seringas é um exemplo irregular, afinal trata-se de materiais perfurocortantes que tem contato com o sangue entre esses usuários (Bastos, 2006).

Retomando a década de 1980, nos Estados Unidos houve a ascensão de um governo conservador e a instalação de políticas públicas. Essas políticas foram criadas para o público "gay", associando o HIV de forma biologicista e estereotipada a esse grupo (Bastos, 2006). Pode-se considerar estereótipo como a atribuição de determinados rótulos que preveem comportamentos nas nossas relações interpessoais e podem estar atrelados a características pessoais atribuídas a pessoas ou a grupos. (Rodrigues; Jablonski \& Assmar, 2005).
Entre essas políticas foram encontradas algumas contradições, a principal defendia o sexo seguro sem o uso de preservativo dividindo opiniões nas populações não religiosas e nas religiosas, pois tal política tinha como intuito a possibilidade de pessoas terem filhos a partir da vontade divina (Bastos, 2006).

Por outro lado, existia uma falta de cuidado por parte da sociedade que culpabilizava as minorias psicológicas, nesta fase o grupo "gay", pela disseminação do vírus HIV na população, e esquecendo que o sexo sem preservativo é uma forma de infecção independente da orientação sexual dos indivíduos. Sendo assim, as relações heterossexuais desprotegidas também foram responsáveis por essa disseminação (Bastos, 2006).

A partir dessa discussão entre os grupos de risco de infecção pelo HIV, se fez necessário focar na redução de danos ocasionados por esse vírus, ou seja, a busca de práticas mais seguras para os indivíduos infectados (Bastos, 2006).

Perante a redução de danos, o indivíduo infectado sai de uma situação mórbida proveniente da doença e passa a ter alternativas terapêuticas para "viver normalmente". A terapia antirretroviral potente (HAART) traz benefícios para a vida do infectado pelo vírus causador da AIDS, porém ela não cura esse indivíduo. Levando-se em consideração que por muito tempo a infecção pelo vírus HIV era associada ao fim da vida, os infectados ao serem diagnosticados, preferiam se isolar da sociedade e não ter mais esperança de viver (Bastos, 2006).

Uma alternativa adicional ao tratamento medicamentoso, foi a inserção do olhar psicossocial em relação a esse indivíduo infectado e a colaboração multidisciplinar da equipe de saúde perante a essa situação. Sendo assim, houve uma ressignificação na vida do soropositivo, levando-se em conta a possibilidade de dar continuidade a sua vida a partir dessas alternativas (Bastos, 2006).

Essas terapias abriram as portas para as pessoas infectadas a partir da consciência de existência de caminhos para o prosseguimento da vida, das relações familiares, conjugais e profissionais desses indivíduos. Mas, essas opções não funcionam da mesma maneira em todos os países. A eficácia dessas possibilidades depende do investimento feito na promoção de saúde e na prevenção de doenças (Bastos, 2006). 
Nota-se que em países desenvolvidos mesmo que existam desigualdades sociais, o valor investido na promoção de saúde e na prevenção de doenças é mais alto do que em países em desenvolvimento. No caso do Brasil e de outros países em desenvolvimento, existe uma distribuição de renda inferior para essas intervenções voltadas à infecção do HIV (Bastos, 2006).

Trazendo dados mais recentes, fora possível concluir que mesmo sendo obrigatória a assistência do SUS relacionada às IST em geral e em particular o HIV, houve um déficit no que tange aquisição de medicamentos e planos municipais e estaduais, além de redução da proporção de ações de promoção e prevenção dessas infecções visando diminuição do estigma da soropositvidade. (Grangeiro et. al, 2012)

É de suma importância ressaltar que, esse vírus não escolhe o "grupo de risco", mas o maior índice dessa infecção está nos locais cujo investimento promoção de saúde e na prevenção de doenças ainda é precário. Além disso, não há possibilidade de erradicar, suspender ou interromper o tratamento do HIV. Sendo assim, existe a necessidade do controle dos tratamentos tanto individuais como coletivos para a perpetuação da vida do portador deste vírus (Bastos, 2006).

Analisando o fato de que a infecção pelo vírus HIV não possui cura, o público alvo ampliou-se. Em 1960 houve a queda da mortalidade infantil e da fecundidade permitindo o aumento da longevidade no Brasil. Isso implica dizer que, a partir dessa década, o Brasil começou a ser um país que teve aumento da população idosa. Assim, o idoso teve um prolongamento na perspectiva de vida, mas por falta de investimento em prevenção e promoção de saúde por parte do SUS, o idoso está exposto a algumas vulnerabilidades, entre essas vulnerabilidades está a infecção pelo HIV ou AIDS em estado avançado (Barboza, 2012).

Com as alterações relacionadas à contaminação do HIV/AIDS, as ocorrências de pessoas diagnosticadas com o vírus ou com a síndrome da imunodeficiência humana tornou-se algo que não se limita apenas a um grupo específico, a atenção deve ser dada a todos de forma igualitária. (Santos \& Assis, 2010)
A população idosa passou a fazer parte do grupo de risco de infecção do vírus da imunodeficiência humana ou do diagnóstico da AIDS em estado avançado, por conta de alguns fatores que corroboram para essa vulnerabilidade epidemiológica. Dentre esses estão a invisibilidade da sexualidade do idoso, o fim da idade reprodutiva e o estereótipo imposto pela sociedade perante esse público. Alguns desses correm pelo preconceito e por falta de promoção e prevenção pelos próprios profissionais de saúde.

Nessa população é comum que ocorra o diagnóstico tardio, pois as práticas sexuais dos idosos não são objetos de estudo, ações e acolhimentos consideráveis por esses profissionais, principalmente na atenção primária cuja população idosa é prioridade desse nível (Barboza, 2012).

Os casos de HIV/AIDS em pessoas acima dos 50 anos têm se tornado mais recorrentes no Brasil, logo, a falta de diagnóstico na fase inicial dificulta o tratamento e acaba provocando o aumento do índice de mortalidade relacionado a essa epidemia (Santos \& Assis, 2010).

Mesmo com a existência de algumas ações, alguns estudos e políticas públicas que já pertencem à população idosa, ainda não são satisfatórios para a prevenção e promoção de saúde. Essas práticas são insuficientes por conta da ausência compreensiva dos profissionais sobre as diferenças subjetivas diante do processo do envelhecimento, inclusive da sexualidade, que está inerente ao mesmo (Silva et al., 2015).

De acordo com Rodrigues, Jablonski \& Assmar (2005) "o preconceito poderia ser definido como uma atitude hostil ou negativa em relação a um determinado grupo, não levando necessariamente, pois, a atos hostis ou comportamentos discriminatórios" (p. 221).

Essa ausência do olhar biopsicossocial ao idoso soropositivo gera no mesmo algumas demandas psicológicas no que se diz respeito às suas relações interpessoais. Considerando a subjetividade do idoso infectado, podem ser levados em conta alguns estigmas, tabus, preconceitos por parte da sociedade como um todo, e nesse todo estão envolvidos os familiares, cônjuges e os profissionais de saúde (Silva et al., 2015). 
Contudo, sabe-se que todo o processo de um soropositivo, desde o diagnóstico até de aprender a dar continuidade à vida, gera muitos impactos. No caso de um soropositivo na terceira idade, esses impactos são mais delicados levando-se em consideração o estereótipo que a sociedade construiu para ele: frágil, debilitado, necessitado de atenção, mas nunca sexualmente ativo. Em contrapartida, a indústria farmacêutica de estimulantes sexuais e o aumento da qualidade de vida do idoso são negligenciados por todos (Cassétte et al., 2016).

Isso implica dizer que, o idoso soropositivo possui demandas psicológicas muito subjetivas no que se diz respeito ao significado dado por ele a essa situação. Mas, ainda assim, existe a necessidade de um trabalho multidisciplinar voltado para o enfrentamento dessa infecção ou na situação de doença. Dentro deste enfrentamento pode-se notar a mudança nas relações afetivas com familiares, cônjuges e amigos; preconceito durante o tratamento e mudanças nas práticas sociais (Cassétte et al., 2016).

Conforme pontuam Santos e Assis (2010), o índice de HIV entre idosos já supera o de adolescentes entre 15 e 19 anos, tornando necessário a criação e implantação de políticas públicas com intuito de reeducação sexual voltada para prevenção e qualidade de vida desse público em questão.

Sexo continua, socialmente, sendo um tabu, e ainda mais quando se trata de idosos, assim "o preconceito e a falta de informação reforçam a ideia da velhice assexuada, o que aumenta a vulnerabilidade do idoso para as DST, entre elas, o HIV/Aids" (Santos \& Assis, 2010, p.149). Esse preconceito parte também dos profissionais de saúde, que adotando de forma tardia posturas adequadas, dificultam o diagnóstico da infecção/doença.

Em nossas relações interpessoais facilitamos nosso relacionamento com os outros se atribuirmos a determinados rótulos, impostos pela sociedade em relação a invisibilidade sexual da pessoa idosa, que são capazes de fazer com que certos comportamentos possam ser antecipados (Rodrigues; Jablonski \& Assmar, 2005).
O diagnóstico tardio do HIV acontece na contramão do serviço de saúde segundo Alencar e Ciosak (2016), "Os profissionais de saúde relataram que no atendimento ao idoso a solicitação da sorologia anti-HIV não era uma rotina adotada no serviço primário de saúde" (p.1142).

Ao chegar ao serviço de saúde, apresentando sinais e sintomas sugestivos, os idosos são submetidos a exames que venham a detectar outras patologias, e não a priori o HIV. Esse comportamento por parte dos profissionais de saúde gera o diagnóstico tardio, o que dificulta o início do tratamento no estágio inicial da doença (Alencar \& Ciosak, 2016).

É importante trazer para essa discussão que estamos no século cujo qualquer informação é encontrada na internet.

Portanto tabus, estigmas e preconceitos por parte dos profissionais de saúde são projetados na forma como o atendimento aos idosos é realizado, tornando esse grupo específico mais vulnerável ao HIV/Aids, por conta principalmente, do diagnóstico tardio. É necessário que haja conscientização por parte desses profissionais para uma melhor promoção de qualidade de vida dessas pessoas através de elaboração de novas políticas públicas em busca da redução da vulnerabilidade, e nesse caso, especificamente, em relação à infecção pelo HIV (Alencar \& Ciosak, 2016).

O psicólogo em sua atuação pode contribuir com a quebra de paradigmas e estereótipos sobre assuntos e questões socialmente abordadas. De acordo com o Código de Ética Profissional do Psicólogo (2005), o princípio fundamental II determina que:

O psicólogo trabalhará visando promover a saúde e a qualidade de vida das pessoas e das coletividades e contribuirá para a eliminação de quaisquer formas de negligência, discriminação, exploração, violência, crueldade e opressão.

Nenhum indivíduo deve ser discriminado pelas escolhas que faz em relação a sua vida sexual. Neste estudo, discriminação é entendida como o tratamento diferenciado, e expressões verbais de desprezo e atos manifestos de agressividade contra uma pessoa ou grupo (Rodrigues; Jablonski \& Assmar, 2005). 
É importante trazer para essa discussão que estamos no século cujo qualquer informação é encontrada na internet. A nossa fonte de buscas sobre esse conteúdo foram as mídias veiculadas na internet sobre o HIV em idosos, o grau de incidência, de informação, depoimentos de soropositivos na terceira idade e suas relações interpessoais perante a infecção.

Assim como no conteúdo pesquisado para compor esses artigos, as mídias trazem vivências de diagnósticos tardios associados ao preconceito, estereótipos e discriminação por parte dos profissionais de saúde, além de grandes incidências nessa faixa etária diante da falta de prevenção pela ausência de reprodução, e a vergonha de ser soropositivo o que gera riscos a vida desse indivíduo e a de seus parceiros.

Pode-se afirmar então, que assim como a ausência de campanhas e políticas públicas direcionadas a transmissão do HIV e a qualidade de vida dos idosos soropositivos, a mídia também abrange de maneira escassa sobre a incidência do HIV e da AIDS na terceira idade. É possível identificar que nesse veículo informativo existe a semelhança entre os conteúdos sobre esse assunto e a importância de abordar e trabalhar a soropositividade na terceira idade visando a promoção da saúde desses indivíduos, assim como são feitos com os adolescentes e com os adultos.

Diante desses fatos nosso objetivo sempre foi trazer para o ambiente acadêmico temas que ainda fossem tabus para a sociedade, no primeiro pré-projeto decidimos falar sobre HIV. Neste momento ainda abordávamos o HIV de maneira muito generalista. Posteriormente apresentamos o HIV com ênfase na transmissão vertical (passada da mãe para o filho), que foi quando tivemos acesso ao primeiro artigo abordando HIV na terceira idade.

Ao iniciar pesquisas por artigos com o tema em questão, notamos o quanto vida sexual e soropositividade na terceira idade ainda são temas abordados e publicados de forma limitada, e quando apresentado em sala de aula, o tema gerava espanto nos ouvintes por conta dos estereótipos do senso comum.

Por mais que nós, estudantes de psicologia, consigamos falar abertamente sobre sexualidade ativa na terceira idade, o tabu sobre este tema é algo que perpassa nosso repertório, é a censura cultural reforçada pelos estereótipos sobre as relações interpessoais da pessoa idosa.
A partir de relatos dos colegas, pudemos compreender o quanto falar sobre diagnóstico tardio de HIV na terceira idade é valioso para a psicologia social e outras áreas da saúde. A insuficiência de material sobre o tema tratado, limitação de políticas públicas voltadas para a vida sexual ativa do idoso e, consequentemente, às infecções sexualmente transmissíveis, nosso estudo contribui para a ciência como um convite à compreensão das relações interpessoais do idoso na contemporaneidade, e a importância da desconstrução de a priores sociais pincipalmente por parte dos profissionais de saúde, com o propósito de facilitar o diagnóstico precoce do HIV.

Diante desses fatos, o presente trabalho tem como problema: Como as mídias informam sobre a atividade sexual do idoso na contemporaneidade? O objetivo geral é analisar a visão das mídias em relação ao sexo na terceira idade. Objetivando especificamente em identificar os motivos dos idosos serem vulneráveis às IST a partir de dados midiáticos; descrever as causas dos preconceitos, estereótipos e discriminações sociais perante a atividade sexual na terceira idade; analisar o papel das mídias como ferramenta informativa sobre HIV na terceira idade.

\section{Método}

Neste estudo foi adotado como método a pesquisa documental, tendo em conta a problemática sobre os obstáculos do diagnóstico do HIV na terceira idade. Segundo Cellard (2014), esse tipo de pesquisa é realizado a partir de fontes ou documentos que englobem os assuntos relacionados. Para alcançar os objetivos desse estudo usamos a pesquisa qualitativa exploratória, pois essa tem como objetivo responder os motivos de algumas variáveis ocorrerem, em determinados fenômenos sociais (Creswell, 2007).

A análise de dados foi realizada a partir de reportagens, consideradas por Cellard (2014), documentos públicos não arquivados a partir das relações sobre as informações contidas no referencial teórico e nas fontes citadas. Segundo Bardin (2011), esse procedimento de análise de dados a partir do conteúdo tem como objetivo as inferências ocorridas diante dos conhecimentos relativos ao referencial teórico e da entrevista por pauta, utilizada como indicador qualitativo nesse projeto. Levando-se em conta os seguintes passos: pré-análise, análise e exploração do material. (p. 95-115) 
O banco de dados utilizados para pesquisar esses documentos foi o site de pesquisa GOOGLE, tendo como critério de inclusão as reportagens que continham discursos de profissionais de saúde sobre HIV na terceira idade, e de idosos soropositivos, ocasionando a exclusão das reportagens que não estavam dentro desse critério. A escolha pelas revistas como fonte de informação deu-se diante ao método documental dessa pesquisa, da necessidade de complementar o artigo com discursos dos profissionais de saúde sobre o HIV na terceira idade e das relações interpessoais dos soropositivos idosos presentes nas reportagens.

O referencial teórico foi construído a partir dos construtos teóricos de estereótipos, preconceito e discriminação (Rodrigues; Jablonski \& Assmar, 2005) e, tomando como base estudos da literatura sobre o tema, selecionamos seis artigos a partir dos seguintes descritores: idosos, HIV/AIDS, vulnerabilidade, veIhice, estigma social e preconceito.

\section{Resultados}

Através de levantamento realizado em sites de busca na internet, utilizando os critérios de inclusão conforme o tema desta pesquisa, foram levantadas diferentes reportagens. Estas reportagens discutiam a experiência de pessoas idosas, em especial a dimensão da sexualidade nesta etapa do ciclo de vida.

Aplicando critérios de inclusão e exclusão, selecionamos as reportagens abaixo (quadro 1) organizadas segundo o título, sujeitos abordados, data de publicação e site hospedeiro. Conclusões gerais sobre a reportagem também são apresentadas no quadro para ilustrar, de forma sucinta, o conteúdo das reportagens.

Quadro 1. Matérias veiculadas na mídia sobre sexualidade na terceira idade

\begin{tabular}{|c|c|c|}
\hline Reportagens & $\begin{array}{c}\text { Sujeitos abordados nas } \\
\text { reportagens }\end{array}$ & Conclusões gerais \\
\hline $\begin{array}{l}\text { "Sou idoso. Sou HIV +" } \\
\text { Publicada no dia } 10 \text { de junho de } \\
2014 \text { no site "Época". }\end{array}$ & $\begin{array}{l}\text { Soropositiva } \\
\text { Profissional de saúde }\end{array}$ & $\begin{array}{l}\text { Relata sobre a vergonha diante do diagnóstico do } \\
\text { HIV e a negligência dos infectados em não contar } \\
\text { para antigas ou atuais parceiras. Além disso, } \\
\text { abrange sobre a resistência da utilização da } \\
\text { camisinha, que é justificada pela idealização da } \\
\text { fidelidade no cônjuge. }\end{array}$ \\
\hline $\begin{array}{l}\text { "Nunca liguei para camisinha", diz } \\
\text { idosa de } 67 \text { anos diagnosticada } \\
\text { com HIV... } \\
\text { Publicada em } 16 \text { de outubro de } \\
2017 \text { no site "UOL". }\end{array}$ & $\begin{array}{l}\text { Soropositivos } \\
\text { Profissional de saúde }\end{array}$ & $\begin{array}{l}\text { A matéria engloba o impacto causado no } \\
\text { diagnóstico tardio na vida da idosa. Apresenta } \\
\text { também, dados estatísticos do aumento da } \\
\text { incidência de HIV na população idosa e frisa a } \\
\text { importância de fazer os exames relacionados a } \\
\text { essa IST. }\end{array}$ \\
\hline $\begin{array}{l}\text { "Número de idosos com HIV no } \\
\text { Brasil cresce } 103 \% \text { na última } \\
\text { década." } \\
\text { Publicada no dia } 18 \text { de março de } \\
2018 \text { no " Correio Braziliense". }\end{array}$ & $\begin{array}{l}\text { Profissional de Saúde } \\
\text { Ministério da Saúde } \\
\text { Ativista e Presidente da ONG } \\
\text { Amigos da Vida }\end{array}$ & $\begin{array}{l}\text { Discorre sobre o aumento de casos de HIV em } \\
\text { idosos e a falta de campanhas informativas sobre } \\
\text { a infecção nos idosos, decorrente do tabu } \\
\text { existente perante assexualidade nessa faixa } \\
\text { etária. }\end{array}$ \\
\hline $\begin{array}{l}\text { "Idosos também precisam se } \\
\text { prevenir contra o HIV" } \\
\text { Publicada no "Portal Dráuzio } \\
\text { Varella" [[S/D]]. }\end{array}$ & $\begin{array}{l}\text { Profissionais de Saúde } \\
\text { Soropositivo }\end{array}$ & $\begin{array}{l}\text { Essa matéria engloba o aumento dos números de } \\
\text { casos de idosos com HIV e outras e. Relata sobre } \\
\text { as dificuldades perante o diagnóstico tardio, mas } \\
\text { ressalta sobre a qualidade de vida oferecida a } \\
\text { essa faixa etária diante dos tratamentos voltados } \\
\text { a essas infecções. }\end{array}$ \\
\hline $\begin{array}{l}\text { 'Minha família me colocou no } \\
\text { fundo do poço por eu ter HIV', diz } \\
\text { idoso sobre ser soropositivo. } \\
\text { Publicada em } 3 \text { de fevereiro de } \\
2019 \text { no Jornal "O ESTADÃO" }\end{array}$ & $\begin{array}{l}\text { Soropositivos } \\
\text { Profissionais de saúde }\end{array}$ & $\begin{array}{l}\text { Apresenta relatos de discriminação, estereotipia e } \\
\text { preconceito contra idosos soropositivos, } \\
\text { especialmente os homoafetivos. Matéria reforça } \\
\text { prevenção e cuidados a saúde como primordiais } \\
\text { para a vida sexual na terceira idade. }\end{array}$ \\
\hline
\end{tabular}




\section{Análise e discussão}

Nesta seção, os dados apresentados na seção de resultados são discutidos considerando os objetivos geral e específicos desta pesquisa. São construídas relações teóricas dos dados deste estudo com os achados da literatura sobre o tema e a fundamentação teórica escolhida para esta pesquisa.

Os dois primeiros objetivos específicos foram abordados em tópicos, enquanto o terceiro objetivo serviu de complemento às análises trazidas nos dois outros.

\section{A vulnerabilidade dos idosos às IST}

Por serem estereotipados pela população como sedentários e assexuados, os idosos tornam-se vulneráveis ao contrair infecções sexualmente transmissíveis. O aumento do número de casos está associado a falta do olhar minucioso e sensível por parte dos profissionais de saúde e de ações direcionadas nas políticas públicas referentes a inclusão dos idosos nos grupos de risco dessas infecções (Alencar \& Ciosak, 2016).

Grande parte das campanhas de conscientização sobre HIV e AIDS tem os jovens como público-alvo, o que criou a impressão de que somente eles estão expostos ao risco de contrair o vírus. Mas pessoas mais velhas também estão vulneráveis: a cada ano, cresce o número de idosos soropositivos no Brasil, e isso não acontece apenas pelo envelhecimento dos pacientes. $\dot{E}$ preciso falar abertamente sobre o tema e alertar esse grupo sobre a importância de se prevenir. (Ribeiro, [S/D])

Trazer a pessoa idosa como ativa nas suas relações interpessoais a partir da visibilidade na mídia, é algo de grande importância para o processo de desconstrução de estereótipos.

Perante a não correlação entre o idoso e a vida sexual ativa, o diagnóstico das infecções, principalmente do HIV, costuma ser feito de maneira tardia em virtude de sintomas amplos que se camuflam em características de outras patologias (Alencar \& Ciosak, 2016).

Segundo o dr. Jean, mesmo quando um idoso com pneumonia, complicação recorrente da aids, chega ao hospital, sua condição sorológica frequentemente não é investigada. É comum que mesmo entre os exames de rotina o teste de HIV não seja solicitado, fazendo com que esses indivíduos só sejam diagnosticados no momento em que eles têm AIDS, ou seja, quando ocorrem as doenças oportunistas (Ribeiro, [S/D]).

Segundo Barboza (2012), os obstáculos referentes ao diagnóstico precoce perpassam entre a não adesão ao teste de HIV em idosos, a falta de atenção e de suporte das equipes de saúde em relação às demandas desse grupo.

A especialista recomenda que as pessoas façam o teste, quando possivel. Quanto antes à infecção é diagnosticada e o tratamento iniciado, maiores as chances de controlar a infecção e a pessoa levar uma vida normal, sem que a infecção evola para AIDS. Éo caso de Maria, ela contou que descobriu a infecção depois de ficar 30 dias internada para tratar uma herpes severa, contraído também por conta de não usar camisinha (Marchezi, 2017).

A não solicitação de exame para detecção de HIV é um comportamento discriminatório que vulnerabilidade o indivíduo, limitando seu acesso à tratamentos adequados.

De acordo com Rodrigues, Assmar e Jablonski (2005) os estereótipos em um primeiro momento facilitam as reações frente ao mundo. Mas reforça que estereotipar impossibilita que vejamos o sujeito com suas idiossincrasias. Os profissionais de saúde têm um papel importante no processo de diagnóstico, é necessário olhar o indivíduo além do estigma social, afinal "quando o estereótipo é suficientemente forte, até os membros do grupo-alvo tendem a aceitá-lo" (p. 212). Assim, nos seguintes trechos de reportagem, temos alguns exemplos deste olhar dos profissionais:

Num dos depoimentos recolhidos, um dos médicos - cujo nome não foi mencionado - diz que não vê necessidade em perguntar sobre sexo. "A gente [comunidade médica] imagina que a sexualidade do idoso é zero. Então não perguntamos nada sobre isso", afirma (Nascimento, 2019).

Além disso, um enfermeiro confessa o seu despreparo. "Não me sinto à vontade para falar com o idoso sobre sexo. Eu me sinto melhor falando disso com uma adolescente, com uma mulher, do que com um homem idoso", revela (Nascimento, 2019). 
O olhar do profissional de saúde perante ao idoso soropositivo não deve assemelhar-se ao senso comum da sociedade, pois julgamento, preconceito, estereótipo e discriminação já fazem parte da rotina dos idosos. É necessário que haja uma visão empática e acolhedora por parte dos profissionais perante essa situação, com o objetivo de ressignificar o sofrimento psíquico do idoso soropositivo diante o diagnóstico. Sendo assim, esse olhar sensível por parte dos profissionais de saúde contribuirá positivamente para a atenção voltada a esse público, para a visibilidade sexual do idoso e para o diagnóstico precoce de HIV.

A pessoa na terceira idade demonstra, em alguns casos, medo do diagnóstico ser revelado provocando constrangimento. A falta de informação sobre a qualidade de vida após o diagnóstico e o tratamento, gera nesse indivíduo portador do vírus a dúvida de possibilidade de continuar tendo relações afetivas, o que gera um aumento significativo de omissões da infecção pelo vírus (Silva et al., 2015).

Passado o susto de ser diagnosticado soropositivo, João voltou a frequentar bailes e a dormir com mulheres que conhece nas pistas de dança. Com algumas, tem encontros de apenas uma noite. Agora, diz que usa preservativo "do começo ao fim". Mas não revela a elas o motivo. "Digo que é para evitar gravidez. Faço a minha parte. Se algo de ruim acontecer, a culpa não será minha, mas do fabricante" (Tavolieri, 2014).

A falta de visibilidade nas mídias torna o idoso soropositivo inibido em falar abertamente sobre sua trajetória como HIV positivo, o que consequentemente contribui para a sua própria vulnerabilidade e a de seus parceiros. A vergonha pessoal é algo que favorece a insegurança desse indivíduo diante dos preconceitos, estereótipos e discriminação, e, portanto, se faz importante investimentos informativos sobre a prudência e a qualidade de vida do idoso soropositivo nas mídias.

Perante a ausência da fertilidade, a pessoa na terceira idade não se preocupa em contrair infecções sexualmente transmissíveis, acreditando que esse fator anula a necessidade do uso do preservativo que tem como finalidade evitar gravidez. O não reconhecimento da vida sexual ativa entre os idosos pela sociedade e pelos profissionais de saúde contribui para impactos psicológicos diante ao diagnóstico (Barboza, 2012).
Fiquei desesperada. Nunca pensei em passar por

isso. Com essas palavras a costureira Maria, de 67 anos, definiu o choque de ser diagnosticada com HIV. "Quando eu pensei que estivesse chegando à fase mais tranquila da minha vida, descobri que deveria ter me prevenido mais. A gente nunca acha que vai acontecer com a gente. Nunca liguei para camisinha"

(Marchezi, 2017).

O diagnóstico feito de maneira adequada pode promover uma melhor qualidade de vida. O trabalho multidisciplinar precisa ser também informativo, promovendo orientações necessárias sobre mudanças no quadro clínico da pessoa diagnosticada com HIV.

"Não adianta culpar ninguém. Eu deveria ter me prevenido. Buscar culpados não aliviaria meu sofrimento. Mas hoje, graças aos medicamentos e ao diagnóstico precoce, consigo levar uma vida normal"

(Marchezi, 2017).

Falar sobre, é promover informação. O que não é abordado, conversado, é tratado com ignorância gerando interpretações distintas que podem ser reforçadas pelo senso comum.

É importante trazer nessa discussão a compreensão do investimento do Sistema Único de Saúde diante a pessoa na terceira idade, mas é necessário ampliar os veículos de informações midiáticas e cartilhas sobre a atividade sexual ativa nessa população. Ainda falta uma percepção mais ampla da soropositividade na pessoa idosa por parte dos profissionais de saúde.

É possível afirmar que a mídia é uma ferramenta importante no processo de pesquisas. A escassez de dados midiáticos sobre sinas, sintomas e soropositivadade na terceira idade é muito grande, existem reportagens que abordam o crescimento da vulnerabilidade dos idosos às infecções sexualmente transmissíveis, ao despreparo das equipes de saúde e da invisibilidade sexual da pessoa da terceira idade. Mas, ainda assim, se faz urgente a necessidade de implementação de informação nos veículos midiáticos que acometam e orientem a equipe multidisciplinar sobre a importância do acolhimento dos idosos soropositivos, e desconstrução de estereótipos sobre o idoso objetivando a diminuição da vulnerabilidade dos mesmos em relação ao HIV. 


\section{Preconceito, estereótipo e discriminação: o tabu sobre HIV na terceira idade}

Segundo Rodrigues, Assmar e Jablonski (2005): “Em Psicologia Social, preconceito é uma atitude negativa dirigida a um grupo e aos que dele fazem parte". No trecho abaixo se pode observar o preconceito da vida sexual ativa na terceira idade.

Existe uma preocupação maior em envelhecer com conforto e com boa saúde. Mas falar abertamente sobre o sexo ainda é um problema. É importante alertar essa população sobre a necessidade do uso da camisinha para que eles tenham uma vida sexual com mais segurança e longe das infecções sexualmente transmissíveis ( Ribeiro, [S/D]).

Acreditar que idosos são assexuados é uma forma de estereotipar o comportamento sexual do idoso, estereótipo "trata-se de uma maneira simplista de atribuir características comuns a todos os membros de um grupo" (Rodrigues, Assmar \& Jablonski, 2005, p. 204).

Mas para que os idosos sejam vistos como indivíduos que têm desejos sexuais, é necessário que haja diálogo em casa e nos consultórios médicos. Também é preciso

criar estratégias educativas através da adoção de políticas de saúde pública que concentrem a atenção na população mais velha e na realização de programas

de prevenção. "Assim, vamos conseguir promover uma mudança no comportamento dos idosos, principalmente quanto às formas de prevenção do HIV. É preciso fazer com que percebam sua vulnerabilidade e entendam a necessidade de se fazer sexo seguro", reforça a médica (Ribeiro, S/D]).

De acordo com Rodrigues, Assmar e Jablonski (2005), estereótipo é a base cognitiva do preconceito, e o componente comportamental é a discriminação. Se a sexualidade ativa do idoso for negligenciada por conta de comportamentos discriminatórios, haverá dificuldade em implantar medidas de prevenção. É importante estarmos atentos a esses comportamentos, afinal os dados mostram que os casos de HIV positivo em pessoas na terceira idade vêm crescendo.

Dados recentes do Boletim Epidemiológico de 2017 apontam que, em 2016, quando foram registrados 1.294 casos, houve o crescimento de $15 \%$ no índice de pessoas acima de 60 anos com o vírus. Em 2015, por sua vez, aumentou 51,16\%, com 1.125 pessoas infectadas, em relação aos números de 2014, quando 856 foram diagnosticados. O pior ano foi 2016, com 2.217 casos (Vinhal, 2018).
Falar sobre sexo na terceira idade é importante para desconstruirmos tabus sobre a vida sexual do idoso afinal, "são nossos limitados recursos cognitivos (...) que nos fazem optar por esses atalhos (...) em outras conduzem aos indesejáveis becos do preconceito e discriminação" (RODRIGUES; ASSMAR; JABLONSKI, 2013, p. 208). Falar sobre é promover informação com finalidade de desconstrução de preconceitos.

Infelizmente, quando eu tomei consciência da importância [de usar camisinha] já era tarde, mas sempre falo para amigos e familiares para que eles se previnam. $O$ arrependimento é muito grande depois

(Marchezi, 2017).

Oportunizar informação é mais uma forma de promover melhor qualidade de vida. Através de orientações, a pessoa na terceira que vem de uma construção limitada sobre sexualidade, e uso do preservativo com finalidade contraceptiva, pode ter acesso aos riscos que ela está exposta tendo relações sexuais sem uso da camisinha.

Analisando o papel das mídias como ferramenta informativa sobre HIV na terceira idade é possível perceber que a presença de informação sobre sexualidade e infecção por HIV nessa mesma faixa etária, possibilita que estigmas sejam descontruídos, desmistifica as crenças sobre assexualidade de pessoas idosas e ausência de vulnerabilidade à IST.

Mesmo não sendo o objetivo principal do trabalho, é importante falar sobre o estigma voltado para a homossexualidade como principal fator de risco para infecção por HIV, mesmo sendo algo muito ultrapassado (os $4 \mathrm{H}$ abordados na introdução). Nestes casos, a pessoa na terceira idade que sofre discriminação por ser idoso e soropositivo, ainda precisa lidar com a solidão por ser homossexual.

Ele avisou a família sobre o problema e, em vez de encontrar amparo, deu de cara com o julgamento e a rejeição dos parentes. "Fui excluído por eles. Só me disseram que se eu tivesse tomado cuidado, eu não estaria assim", recorda (Nascimento, 2019).

Situações como esta, associadas ao comportamento hostil em relação ao idoso homossexual portador de HIV, Rodrigues, Assmar e Jablonski (2013, p. 222) denominam esse público de Bode Expiatório, que é o público escolhido pela sociedade para levar a culpa mesmo sendo inocente. 
O preconceito em torno de sua homossexualidade, da idade avançada e da doença ainda moldam a visão negativa da familia sobre ele, o que Ihe trouxe dificuldades. (Nascimento, 2019).

Ter matérias e depoimentos que abordam o tema deste artigo, publicita que a sociedade reconheça a importância de incluir a pessoa na terceira idade como ativa em suas relações interpessoais. A Psicologia Social tem como objetivo compreender a população estudada sem corroborar com o senso comum, visando que o nosso trabalho também engloba a subjetividade humana sem a priores. Pode partir de nós a desconstrução de preconceitos, julgamento e estereótipos dos profissionais de saúde e ressignificar essas demandas em forma de informação para a sociedade.

\section{Considerações finais}

Através dos resultados apresentados foi possível perceber que as questões trazidas na construção deste artigo, por meio dos materiais de estudo base, foram abordadas de maneira sucessiva sendo associadas e reforçadas pelas mídias.

Preconceito, estereótipo e discriminação são manifestações que são dirigidas ao idoso soropositivo na contemporaneidade corroborando com o diagnóstico tardio do HIV. Essas manifestações ocorrem pela crença construída socialmente que a pessoa na terceira idade não faz parte do grupo de risco de infecção pela Vírus da Imunodeficiência Adquirida, por não possuir vida sexual ativa. Diante desta problemática, se faz necessário ser trabalhado nas políticas públicas questões sobre soropositividade de pessoas na terceira idade.

As intervenções podem ser feitas através da criação de campanhas, cartilhas e outras sobre a importância do uso do preservativo, do olhar humanizado do profissional de saúde voltado para a população idosa através de imparcialidade na atuação profissional e a superação de uma visão de senso comum durante sua prática profissional. É preciso ter esse olhar mais sensibilizado aos sinais e sintomas da doença, para que o tratamento possa ser praticado na fase inicial da infecção.
Em face das questões abordadas, foi possível perceber a necessidade de aumento de estudos sobre a vida sexual do idoso, e sobre riscos de infecções por HIV durante $o$ ato sexual, afinal a quantidade de trabalhos encontrados sobre este tema durante nossas buscas em ferramentas acadêmicas, ainda parece insuficiente.

Um estudo documental apresenta certos limites, como outros métodos de estudo também. Assim, através de dados documentais, temos um retrato de um momento do fenômeno que foi construído por outra pessoa que, balizado por sua subjetividade, pode resguardar a nossa visão pessoal sobre o tema. Longe de invalidar os resultados, isso aponta também para a necessidade de complementariedade entre as pesquisas sobre o tema, utilizando dados de entrevistas, de questionários, de experimento, entre outros. Este artigo, que utilizando uma abordagem documental objetivou trazer contribuições ao olhar sobre o HIV/AIDS na terceira idade, se insere no esforço de ampliar o debate sobre o tema, na esfera acadêmica e profissional, mas também na esfera cotidiana.

\section{Contribuições dos autores}

Fonseca A. B. participou da concepção, delineamento, buscae análise dos dados da pesquisa,coleta e interpretação de dados da pesquisa, interpretação dos resultados, redação do artigo científico. Batista M. A. S participou da concepção, delineamento, busca e análise dos dados da pesquisa,coleta e interpretação de dados da pesquisa, interpretação dos resultados, redação do artigo científico. Santana R. R. C. participou da concepção, delineamento, análise dos dados da pesquisa, interpretação dos resultados, redação e encaminhamento do artigo científico.

\section{Conflitos de interesses}

Nenhum conflito financeiro, legal ou político envolvendo terceiros (governo, empresas e fundações privadas, etc.) foi declarado para nenhum aspecto do trabalho submetido (incluindo, mas não se limitando a subvenções e financiamentos, participação em conselho consultivo, desenho de estudo, preparação de manuscrito, análise estatística, etc.). 


\section{Referências}

Alencar, R. A., \& Ciosak, S. I. (2006). Aids em idosos: motivos que levam ao diagnóstico tardio. Revista Brasileira de Enfermagem, 69(6), 1140-1146. Recuperado de http://www. scielo.br/pdf/reben/v69n6/0034-7167-reben-69-06-1140. pdf. doi: $\underline{10.1590 / 0034-7167-2016-0370}$

Barboza, R. (2012). Homens idosos e o HIV/Aids no campo da Saúde Coletiva: vulnerabilidades e desafios na quarta década da epidemia. Boletim do Instituto de Saúde, 14(1), 81-89. Recuperado de http://periodicos.ses.sp.bvs.br/pdf/ bis/v14n1/v14n1a10.pdf

Bardin, L. (2011). Organização da análise. In L. Bardin. Análise de conteúdo (2a ed., Cap. 1 terceira parte, pp. 95-115). Lisboa: Edições 70 .

Bastos, F. I. (2006). Aids na Terceira Década (v. 20). Rio de Janeiro: Fundação Oswaldo Cruz.

Cassétte, J. B., Silva, L. C., Felício, E. E. A. A., Soares, L. A., Morais, R. A., Prado, T. S., ... Guimarães, D. A. (2016). HIV/aids em idosos: estigmas, trabalho e formação em saúde. Revista Brasileira de Geriatria e Gerontologia, 19(5), 733-744. Recuperado de http://www.scielo.br/pdf/rbgg/v19n5/ pt_1809-9823-rbgg-19-05-00733.pdf. doi: 10.1590/180998232016019.150123

Cellard, A. (2014). A Análise documental. In J. Poupart, J. P. Deslauriers, L. H. Groulx, A. Laperriere, R. Mayer, \& A. Pires. A Pesquisa qualitativa: Enfoques epistemológicos e metodológicos (4a ed, Parte III. pp. 295-316). Petrópolis: Vozes.

Código de ética profissional do psicólogo. (2005). Brasília: Conselho Federal de Psicologia. Recuperado de http://site. cfp.org.br/wp-content/uploads/2012/07/codigo-de-eticapsicologia.pdf

Creswell, J. W. (2007). Procedimentos qualitativos. In J. W. Creswell. Projeto de pesquisa: Métodos qualitativos, quantitativos e mistos (2a ed., Cap. 10, pp. 184-210). Porto Alegre: Artmed.

Grangeiro, A., Escuder, M. M. L., Silva, S. R., Cervantes, V., \& Teixeira, P. R. (2012). Características da Resposta à Aids de Secretarias de Saúde, no Contexto da Política de Incentivo do Ministério da Saúde. Revista Saúde e Sociedade, 21(4), 954-975. Recuperado de https://www.scielosp.org/pdf/ sausoc/2012.v21n4/954-975/pt. doi: 10.1590/S010412902012000400014
Marchezi, F. (2017). "Nunca liguei para camisinha", diz idosa de 67 anos diagnosticada com HIV [Site]. Recuperado de https://noticias.uol.com.br/saude/ultimasnoticias/ redacao/2017/10/16/nunca-liguei-para-camisinha-dizidosa-de-67-anos-diagnosticada-com-hiv.htm

Nascimento, C. (2019). 'Minha família me colocou no fundo do poço por eu ter HIV', diz idoso sobre ser soropositivo [Site] Recuperado de https://emais.estadao.com.br/noticias/ comportamento, minha-familia-me-colocou-no-fundodo-poco-por-eu-ter-hiv-diz-idoso-de-73-anos-sobre-sersoropositivo,70002703813

Ribeiro, M. [S/D]. Idosos também precisam se prevenir contra o HIV [Site]. Recuperado de https://drauziovarella.uol.com.br/ reportagens/idosos-tambem-precisam-se-prevenir-contrao-hiv/

Rodrigues A., Jablonski, B., \& Assmar, E. M. L. (2005). Preconceito, estereótipos e discriminação. In A. Rodrigues, E. M. L. Assmar \& B. Jablonski (Orgs.), Psicologia Social (30a ed, pp. 198-240). Petrópolis: Vozes.

Santos, A. F. M., \& Assis, M. (2011). Vulnerabilidade das idosas ao HIV/AIDS: despertar das políticas públicas e profissionais de saúde no contexto da atenção integral: revisão de literatura. Revista Brasileira de Geriatria e Gerontologia, 14(1), 147-157. Recuperado de http://www.scielo.br/ pdf/rbgg/v14n1/a15v14n1.pdf. doi: 10.1590/S1809$\underline{98232011000100015}$

Silva, J., Saldanha, A. A. W., \& Azevedo R. L.W. (2010). Variáveis de impacto na qualidade de vida de pessoas acima de 50 anos HIV+. Psicologia: Reflexão e Crítica, 23(1), 56-63. Recuperado de http://www.scielo.br/pdf/prc/v23n1/ a08v23n1.pdf. doi: 10.1590/S0102-79722010000100008

Silva, L. C., Felício, E. E. A. A., Cassétte, J. B., Soares, L. A., Morais, R. A., Prado, T. S., ... Guimarães, D. A. (2015). Impacto psicossocial do diagnóstico de HIV/aids em idosos atendidos em um serviço público de saúde. Revista Brasileira de Geriatria e Gerontologia, 18(4), 821-833. Recuperado de http://www.scielo.br/pdf/rbgg/v18n4/ pt_1809-9823-rbgg-18-04-00821.pdf. doi: 10.1590/18099823.2015.14156

Tavolieri, N. (2014). Sou idoso. Sou HIV + [Site]. Recuperado de https://epoca.globo.com/vida/noticia/2014/06/soubidosob-sou-bhiv-b.html.

Vinhal, G. (2018). Número de idosos com HIV no Brasil cresce 103\% na última década [Site]. Recuperado de https:// www.correiobraziliense.com.br/app/noticia/ciencia-esaude/2018/03/25/interna_ciencia_saude,668253/numerode-idosos-com-hiv-no-brasil-cresce-103-na-ultima-decada. shtml 